\title{
UN SAN JUAN BAUTISTA FIRMADO POR JUAN SIMÓN GUTIÉRREZ
}

El conocimiento de la pintura sevillana de la segunda mitad del siglo XVII supone uno de los grandes retos de nuestra historiografía artística. Efectivamente, el amplio abanico de discípulos e imitadores del arte de Murillo necesita una profunda revisión metodológica que sepa clarificar la nada fácil tarea de aislar las distintas personalidades que constituyen este importante grupo de artistas. En este sentido la personalidad de Juan Simón Gutiérrez (h.1634-1724) continua siendo bastante confusa si bien con algunos interrogantes se le van atribuyendo ciertas obras que puedan responder al todavía escaso conocimiento de su estilo frente al amplio grupo de pintores pertenecientes a la escuela de Murillo.

Este inédito San Juan Bautista predicando en el desierto (fig. 1), firmado por Juan Simón Gutiérrez (figs. 2-3) procedente de una colección cordobesa constituye un importante hallazgo que contribuye a conocer más el escasísimo catálogo de este pintor ${ }^{1}$. La obra de este interesante artista permanecía circunscrita tan sólo a las dos únicas obras firmadas: La Virgen y el Niño con San Agustín, San Nicolás de Tolentino, Santa Mónica y Santa Rita de Casia (1698) conservada en el Convento de Agustinas de la Santísima Trinidad de Carmona; y Santo Domingo confortado por la Virgen y Santas Mártires (1710) perteneciente al Museo de Bellas Artes de Sevilla, última referencia conocida del pintor ${ }^{2}$. Precisamente en función de estas dos obras firmadas por Juan Simón Gutiérrez se ha podido ir atribuyéndole un conjunto de pinturas manifestadas por Enrique Valdivieso (San Joaquín y Santa Ana ${ }^{3}$, Museo de Bellas Artes de Sevilla) y Diego Angulo (La Asunción de la Virgen ${ }^{4}$, Wallace Collection de Londres.) En parte la dificultad para definir la figura de Juan Simón Gutiérrez, lo mismo que ha ocurrido en el caso de otros artistas sevillanos pertenecientes al último tercio del siglo xvir fue la ingente producción de verdaderos talleres murillescos como los de Francisco Meneses Osorio (h.16401721) y Esteban Márquez de Velasco (1652-1696) a los que se iban asignando muchas obras que, aunque a veces difieren del estilo del maestro, pueden encajar en el amplio concepto y variedad de un taller.

Junto a estas importantes observaciones hay que hablar también de los escasísimos documentos conocidos hasta ahora para poder completar así su biografía. Aunque nacido en Medina Sidonia (Cádiz) sabemos que pronto de traslada a Sevilla donde asegura Ceán Bermúdez que asistió a la Academia de 1664 a $1672^{5}$. Gracias a Gestoso Pérez conocemos el nombre de sus padres así como su matrimonio ${ }^{6}$, pero sobre todo fue Enrique Hormigo quien dio a conocer el documento más importante: la partida de bautismo del pintor con fecha de cuatro de junio de 1634. Este descubrimiento supone revisar la veracidad de un documento que data de 1691 donde anota con motivo de un censo que «Ju(an) Cimon Gutierrez Maestro natural de Medina Cidonia de edad de quarenta y ocho años es cassado» ${ }^{7}$. Efectivamente, este último escrito dado como válido desde su descubrimiento en 1900 dejaba claro que 1643 era la fecha de nacimiento de nuestro pintor ${ }^{8}$. Únicamente, Diego Angulo rehusó este documento por parecerle

\footnotetext{
' Mide $165 \times 123 \mathrm{~cm}$. El autor agradece a la propietaria de esta obra su generosa colaboración en la catalogación de esta obra.

${ }^{2}$ Enrique Valdivieso y Juan Miguel Serrera, La época de Murillo: Antecedentes y consecuentes de su pintura, Sevilla, 1982, pp. 174-175.

${ }^{3}$ Diego Angulo Iñiguez, Murillo. Su vida, su arte, su obra, 3 vols, Madrid, 1990, pp. 582-584.

${ }^{4}$ Diego Angulo Iñiguez, Murillo y su escuela en colecciones particulares, Sevilla, 1975, p. 8.

${ }^{5}$ Juan Agustín Ceán Bermúdez, Diccionario de los más ilustres profesores de las Bellas Artes en España, Madrid, 1900, pp. $250-251$.

${ }^{6}$ Sus padres se llamaban Juan Simón Gutiérrez y María de la Paz, y su esposa María Navarro de Córdoba. José Gestoso Pérez, Ensayo de un diccionario de los artífices que florecieron en esta ciudad de Sevilla desde el siglo XIII hasta el XVIII (1899-1908), t. 2, pp. 47-48.

${ }^{7}$ Diario de Cádiz, 5-12-1997.

${ }^{8}$ Enrique Valdivieso, Historia de la pintura sevillana. Siglos XIII al XX, Sevilla, 1986, p. 245.
} 

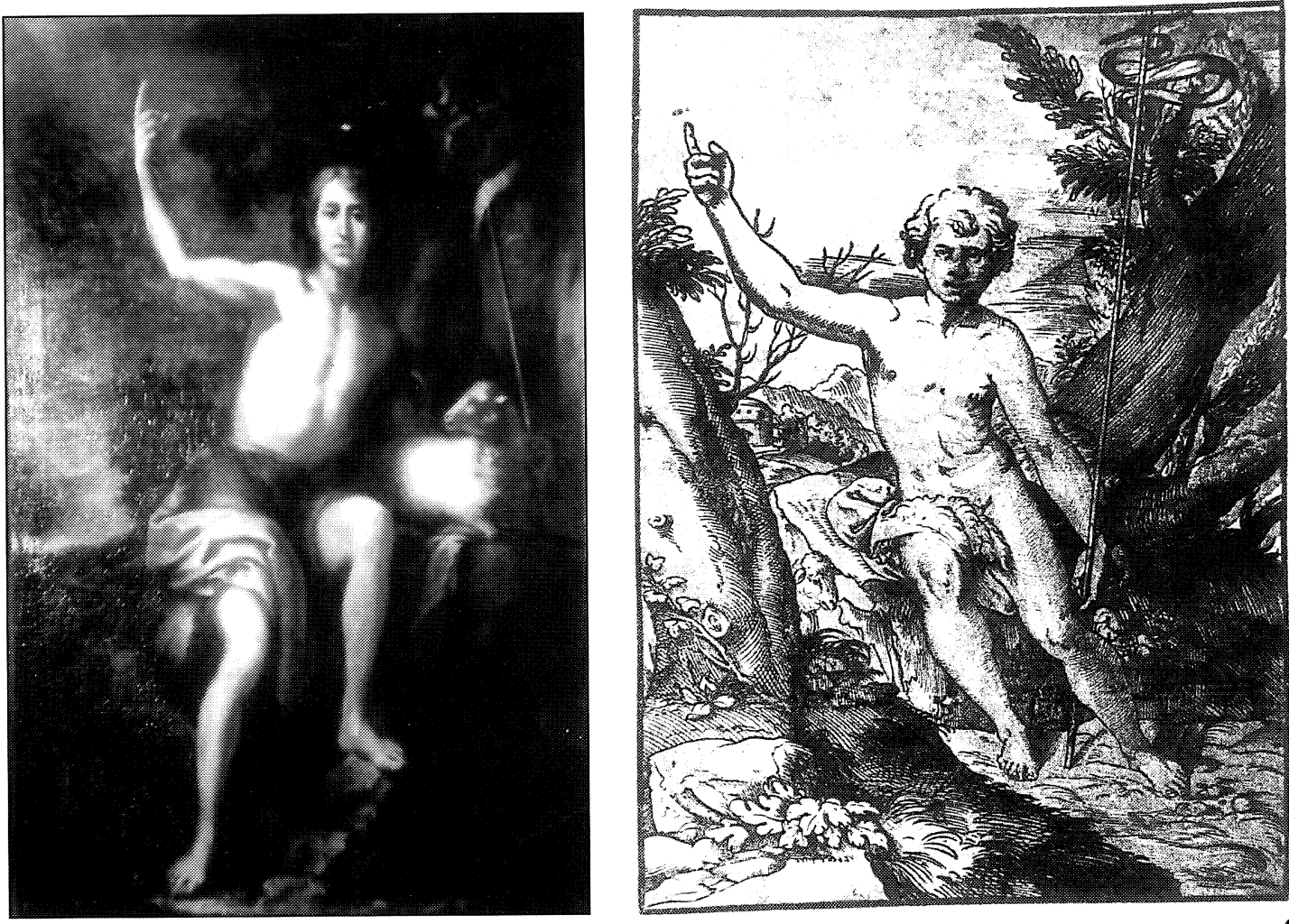

2
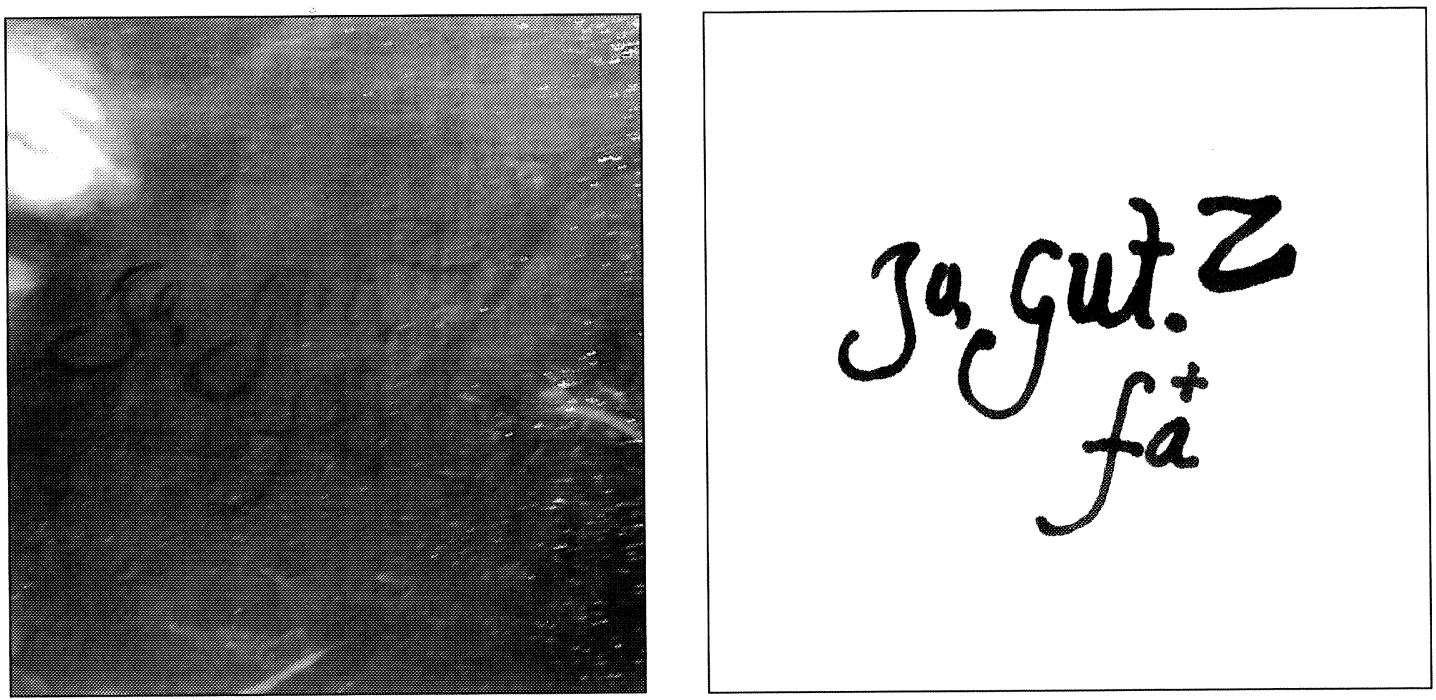

Fig. 1. Juan Simón Gutiérrez, San Juan Bautista predicando en el desierto, Córdoba, Colección particular

Fig. 2. Juan Simón Gutiérrez, San Juan Bautista predicando en el desierto (detalle firma), Córdoba, Colección particular. Fig. 3. Juan Simón Gutiérrez, San Juan Bautista predicando en el desierto (transcripción de la firma).

Fig. 4. Ugo di Carpi, San Juan Bautista predicando en el desierto, xilografía sobre composición de Rafael.

AEA, LXXVI, 2003, 304, pp. 407 a 436 
improbable que Juan Simón Gutiérrez hubiera nacido mucho después de 1645 si había asistido a la Academia de Sevilla desde $1664{ }^{\circ}$. Desconocemos la existencia de otros datos que nos ayuden a conocer la formación de Gutiérrez como pintor aunque es evidente en toda su obra la enorme filiación hacia los modelos murillescos.

La escena se desarrolla sobre un paisaje crepuscular de suaves tonalidades azuladas que hacen destacar mejor la hercúlea figura de un joven San Juan Bautista sentado sobre un cobijo natural excavado en la roca. Escaso de ropas, viste una piel de camello reflejo de su vida penitente en el desierto. El artista ha dispuesto oblicuamente la figura del santo hacia el cordero de Dios que junto a la esbelta cruz de caña compone una verdadera pirámide de gran dinamismo y luminosa monumentalidad. El contraste entre los bellos azules del celaje y los tonos castaños dorados del roquedo corresponden a la caracterización que hace Palomino del arte del pintor cuando afirma que, «imitó muy bien las tintas y hermosuras del colorido de su maestro» ${ }^{10}$.

En cuanto a los modelos tanto los rasgos personalísimos del San Juan Bautista como el tratamiento de los pliegues son exactamente los mismos que aparecen en las dos únicas obras firmadas por Juan Simón Gutiérrez. El rostro del San Juan presenta igualmente relación con La Virgen y el Niño con Santos Agustinos del Convento de la Santísima Trinidad de Carmona. Estos rasgos faciales - boca estrecha y marcado tabique nasal- tan característicos en la estética de este pintor han permitido atribuir con cierta seguridad otras obras no firmadas salidas de sus manos. Estamos pues ante un lienzo de indiscutible atribución por sus modelos y su técnica que responde a la demanda de una importante clientela que destinaba este tipo de obras para revestir iglesias o conventos. Efectivamente, la ciudad de Sevilla profesó a los Santos Juanes una gran devoción desde finales del siglo XVI hasta la segunda mitad del siglo XVII ${ }^{11}$. Entre muchos ejemplos destacan las obras de Juan de Roelas (1609) y Francisco Polanco $(1651)^{12}$.

Pasando al estudio de las fuentes grabadas utilizadas por Juan Simón Gutiérrez para la realización de este San Juan Bautista predicando en el desierto advertimos la combinación de dos estampas distintas. Primeramente, nuestro artista encontró en el San Juan Bautista de Rafael (Galería de los Uffizi, Florencia) su fuente de inspiración, conocido a través de alguna estampa italiana de las muchas que debieron circular por aquellos talleres ${ }^{13}$. Este modelo al igual que la mayor parte de las composiciones de Rafael fueron grabadas por Marco Antonio Raimondi (h. 480-1539) quien creó un importante taller dedicado a copiar y difundir los modelos del maestro de Urbino ${ }^{14}$. Muy cercano es el eco que en Gutiérrez produce el San Juan Bautista grabado al claroscuro por el italiano Ugo da Carpi (1480-1523) (fig. 4) ${ }^{15}$. Fundamental en ambas figuras es el gesto del brazo apuntando hacia lo alto, así como la desnudez y la manera de sostener el báculo. La diferencia estriba en que el torso está invertido afectando lógicamente a la correcta posición de las piernas. Además el cordero ha tomado protagonismo al situarse casi frontalmente bajo el costado izquierdo del Bautista.

Mayor interés muestra el modo en como Juan Simón Gutiérrez manipuló la segunda estampa, esta vez de Cornelis Cort (1533-1578) sobre una composición de Francesco Salviati (fig. 5) ${ }^{16}$. La estampa fue utilizada por el pintor para realizar en un segundo plano la escena

${ }^{9}$ Diego Angulo Iñiguez, Murillo. Su vida... op. cit., 1990, t. 3, p. 353.

${ }^{10}$ Antonio Palomino, Museo Pictórico y Escala Óptica con el Parnaso español pintoresco y Laureado, Madrid, 1947, pp. 120-121.

11 Enrique Valdivieso, catal. exp., Bartolomé Esteban Murillo (1617-1682), Londres-Madrid, 1983, p. 55.

${ }^{12}$ El cuadro de Roelas pertenece a la colección de la casa ducal de Medina Sidonia y el Francisco Polanco se encuentra en la Catedral de Sevilla.

${ }_{13}$ San Juan Bautista en el desierto (1518-20 circa), lienzo, 165 x $147 \mathrm{~cm}$, Florencia, Gallerie Uffizi, Inv. $1890, \mathrm{n} .1446$.

${ }^{14}$ Benito Navarrete Prieto, La pintura andaluza del siglo XVII y sus fuentes grabadas, Madrid, 1998, p. 267.

${ }^{15}$ Bartsch, A., The Illustrated Bartsch, Italian Chiaroscuro Woodcuts, Nueva York, 1980, t. 12, p.108. núm. 18.73.

${ }^{16}$ Bartsch, A., The Illustrated..., op. cit., t. 52, 1986, p. 69. 


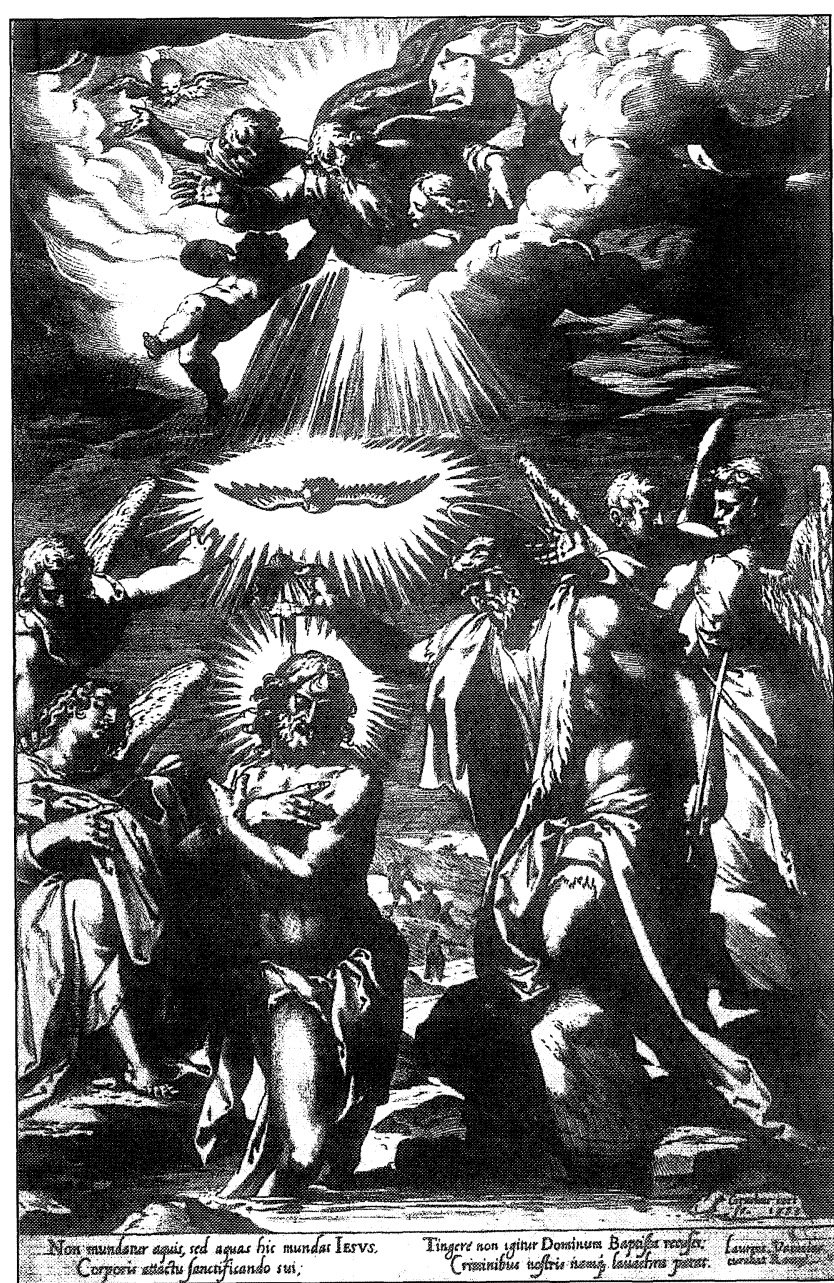

Fig. 5. Cornelis Cort, El Bautismo de Cristo, grabado sobre composición de Franceso Salviati. del Bautismo de Cristo que se halla en el extremo inferior izquierdo de la composición aumentando en su conjunto la capacidad descriptiva y narrativa de la obra al colocar dos escenas distintas de una misma historia en diferentes planos del cuadro. Es curioso observar como Gutiérrez al igual que lo hiciera en su obra $L a$ Virgen y el Niño con Santos Agustinos halla recurrido una vez más a una estampa de Cort sobre composición de Zuccaro para representar una escena ${ }^{17}$. Como ha señalado Benito Navarrete no nos debe extrañar la enorme proliferación que tuvieron las estampas de Cort sobre modelos de artistas italianos en el ámbito de los discípulos de Murillo ${ }^{18}$.

Por último, dado el escaso número de obras firmadas y fechadas por Juan Simón Gutiérrez es de enorme dificultad precisar por la técnica una evolución estilística y cronológica que sea fiable. Si bien, este San Juan Bautista presenta rasgos tenebristas confundidos con formas más blandas y suaves propias de la estética murillesca cabría pensar en una etapa de transición equiparable a la que sufrió la escuela pictórica sevillana a mediados del siglo XVII cuando la corriente

naturalista de Zurbarán acusaba la influencia de Murillo. Es arriesgado afirmar que la presente obra fue ejecutada durante esta transición estilística ya que nos encontraríamos con un jovencísimo Juan Simón de a penas diecisiete años. Por el contrario, al igual que las obras de Murillo y sus discípulos no siempre se alinean en una evolución estética estable habría que considerar a Juan Simón Gutiérrez como un pintor de poderosa filiación murillesca que supo adaptar su estilo a las cambiantes exigencias de una caprichosa clientela.

José Luis ReQuena Bravo de Laguna Universidad de Navarra

\footnotetext{
${ }^{17}$ Benito Navarrete Prieto, La pintura andaluza... op. cit., 1998, p. 136.

${ }^{18}$ Ibídem, p. 136.
} 